\title{
EDITORIAL
}

\section{REINICIAR, CONTINUAR}

O ano de 2017 iniciou-se, não sem grandes turbulências no âmbito político e acadêmico. Os processos conduzidos no âmbito macro de redução do tamanho do estado e, por consequência, dos direitos sociais continuam a todo vapor nesta passagem de ano. Acompanhadas (ou até mesmo alimentadas) por um jogo semântico no qual "direitos" se transformam em "privilégios" e as "reformas" são soluções únicas para um Estado "falido", essas mudanças vem remendar a Constituição, descaracterizando seus princípios e promovendo a manutenção (ou fortalecimento) da desigualdade social.

Se as festas dos solstícios de verão, seguidas pelas férias, nos despertam a sensação de recomeço, 2017 chegou mostrando-nos que é preciso continuar o estudo, o debate, o movimento e a luta. Nós do PPGE-UNIMEP continuamos nesse movimento, sendo o debate sobre a Reforma da Previdência, que realizamos em 15 de março deste ano, uma de nossas mais recentes ações.

No âmbito acadêmico, este ano é o início de um novo ciclo avaliativo dos programas de pós-graduação. É o ano das Notas dos programas, dos Qualis das revistas e dos livros e de intensos debates sobre o que esses números representam, sob quais critérios eles foram construídos e de que maneira eles formatam e normatizam nossas práticas como docentes e pesquisadores.

Modelos matemáticos convertem recortes da realidade em números e não são capazes de exprimir a complexidade do trabalho educativo. Mas eles estão cada vez mais presentes como modeladores de nossas ações, tensionando os aspectos formativo e investigativo de nosso trabalho com palavras como "produtos" e "pontos".

Iniciamos este ano preocupados. E queremos continuar o debate sobre os impactos dessas condições na educação no Brasil e no Mundo. É o que esperamos deste veículo de divulgação de pesquisas.

Neste número de 2017, trazemos artigos de fluxo contínuo e um dossiê, voltando nosso olhar para Brasil, Portugal e Estados Unidos. Os artigos em fluxo contínuo são oriundos de autores dos estados de São Paulo e Paraná e tratam de temáticas voltadas à leitura/ escrita, formação de professores, judicialização das políticas educacionais e autoridade na sociedade moderna.

O dossiê "Investigações sobre as práticas de ensino de Ciência e Tecnologia", organizado pelos professores J. Bernardino Lopes, da Universidade de Trás-os-Montes e Alto 
Douro (UTAD), em Vila Real - Portugal, e Maria Guiomar Carneiro Tommasiello, da UNIMEP, traz artigos de autores brasileiros (do estado de São Paulo) e de Portugal (de Lisboa, Porto, Vila Real e Aveiro). Sobre as temáticas dos artigos do dossiê, remetemos o leitor à apresentação dos autores. Com relação aos artigos recebidos em fluxo contínuo, seguem nossas breves notas de indicação de leitura.

O artigo "Saberes dos supervisores no contexto do PIBID: formação e parceria", de Laura Noemi Chaluh, Bétsamar Scopinho Martins, Maria Antonia Ramos de Azevedo e Andreia Osti discute o lugar dos supervisores do PIBID, problematizando seus saberes. As autoras estiveram diretamente envolvidas no programa, uma delas como supervisora, e, portanto, participaram do desenvolvimento do trabalho e puderam, neste sentido, legitimar a escola como lugar tanto de formação quanto de produção de saberes e compreender, o que foi confirmado pelos bolsistas do projeto.

O artigo "Formação docente: contribuições da diversificação dos instrumentos avaliativos", de Mari Clair Moro Nascimento, Raquel Lazzari Leite Barbosa, e Anelise Martinelli Borges de Oliveira, analisou o impacto do uso de diferentes instrumentos de avaliação em uma disciplina de ensino superior. A partir da análise de conteúdo do questionário dos alunos participantes, as autoras puderam observar o caráter formativo dessa diversificação nas práticas avaliativas, especialmente por se tratar de uma disciplina que estudava esse tema, bem como reforçar a necessidade (tão premente) de superar o caráter meramente verificador da avaliação.

O artigo "Tentativas de apropriação da linguagem acadêmica por estudantes universitários: a produção escrita na universidade", de Milena Moretto, traz à baila o debate sobre a produção escrita de estudantes universitários. A partir da análise de TCCs de um grupo de alunos do curso de Administração de Empresas, a autora destaca as estratégias que os alunos utilizam para tentar se apropriar e dar respostas ao gênero específico de um trabalho de conclusão. Os resultados apontam para a necessidade de se considerar o ensino da escrita acadêmica para além da mera apresentação de normas e padronizações, caminhando para uma discussão sobre o gênero textual.

O artigo "Hipertexto: a formação de um leitor como autor", de Jean Custódio de Lima e Dagoberto Buim Arena discute a construção de um aluno leitor/autor no processo de interação com hipertextos. A partir de uma revisão bibliográfica sobre o tema, os autores destacam as potencialidades do uso das TIC para a formação de alunos produtores autônomos de textos.

$\mathrm{O}$ artigo "Exigibilidade judicial do direito à educação: interfaces entre educação e judiciário na produção norte-americana“, de Marina Feldman e Adriana Aparecida Dragone Silveira, traz uma revisão dos estudos na base Eric da judicialização da educação nos EUA. Essa revisão ajuda a fomentar o debate a respeito do lugar da qualidade da educação e da efetividade de levar as políticas públicas para o âmbito do Poder Judiciário. Dentre os diversos resultados da pesquisa, destaque para a grande quantidade de trabalhos (cerca de 30\%) que podem ser agrupados no eixo "Segregação racial, cultural, étnica ou socioeconômica". 
O artigo "Metamorfoses da autoridade: apontamentos sobre a noção de autoridade na cultura hodierna", de Luiz Antônio Calmon Nabuco Lastória e Juliana Rossi Duci, parte da teoria crítica, em especial de suas bases psicanalíticas, para analisar as transformações que a modernidade provocou na autoridade tradicional. O texto nos provoca a pensar como os deslocamentos da autoridade em uma sociedade das TIC interpelam o papel (e a autoridade) dos professores como formadores das novas gerações.

Continuemos,

Thiago Borges de Aguiar 
